Western University

Scholarship@Western

Western Libraries Publications

Western Libraries

6-29-2017

\title{
Data-informed Open Education Advocacy: A New Approach to Saving Students Money and Backaches
}

Sydney Thompson

North Carolina State University

Lillian S. Rigling

Western University, lrigling@uwo.ca

Will Cross

North Carolina State University

John Vickery

North Carolina State University

Follow this and additional works at: http://ir.lib.uwo.ca/wlpub

Part of the Archival Science Commons

Citation of this paper:

Thompson, Sydney; Rigling, Lillian S.; Cross, Will; and Vickery, John, "Data-informed Open Education Advocacy: A New Approach to Saving Students Money and Backaches" (2017). Western Libraries Publications. 62.

http://ir.lib.uwo.ca/wlpub/62 


\title{
Data-Informed Open Education Advocacy: A New Approach to Saving Students Money and Backaches
}

Sydney Thompson, John Vickery, Lillian Rigling, Will Cross

\section{Shortened title: Data-Informed Open Education Advocacy}

\begin{abstract}
:
The North Carolina State University (NCSU) Libraries has long recognized the financial burden textbook costs place on students. By crosswalking information on use of our textbook collection with textbook cost and course enrollment data, we have begun to map the environment for textbook use at the university and identified opportunities for faculty outreach in promoting alternatives to traditional textbooks, including our Alt-Textbook program. This article describes our programs, our investigation of textbook use patterns, and how we are using this data to inform our practice.
\end{abstract}

\section{Introducing the Textbook Lending Program and NCSU Culture}

The North Carolina State University (NCSU) Libraries has long recognized the financial burden textbook costs place on students. This aligns with the university's strategic goal on "Driving Student Success with Strategic Planning." To support the success of our students and help alleviate this hardship, we offer both a popular textbook lending program and grants to support faculty adoption of open educational resources (OERs). In 2016 we endeavored to bridge these efforts by utilizing data from the textbook program to inform advocacy for OER adoption. By crosswalking information on use of the textbook collection with textbook cost and course enrollment data, we have begun to map the environment for textbook use at the university and identified opportunities for faculty outreach in promoting alternatives to traditional textbooks. This article describes our programs, our investigation of textbook use patterns, and how we are using this data to inform our practice. 


\section{The Textbook Lending Program in the NCSU Libraries}

The NCSU Libraries launched a textbook lending program in 2009 in response to a student-led proposal submitted to our University Library Committee. Designed to reduce the burden of rising textbook costs on our student population, this program involves partnering with our campus bookstore to provide one copy of every required textbook for fall and spring semester courses. At the beginning of every fall and spring semester, the NCSU Bookstores provides the Libraries with a list of every required textbook. Our Acquisitions and Discovery department then deduplicates this list, cross-referencing it against our current holdings, and acquires the titles we do not own from the Bookstores. We spend between $\$ 30,000$ and $\$ 40,000$ of our collections budget each year to fund the textbook program, which is less than one percent of our annual allocation for monographs. In the first year, we purchased approximately 1,200 textbooks to seed the collection, and we now purchase around 700 textbooks each year. Where titles are available from our general collection, Acquisitions and Discovery provides the Access Services department with a list of titles to be pulled as textbooks. Textbooks are added to a "Textbook Collection" in our online catalog and interfiled with our other Course Reserves at the Ask Us service point in each library, where they are available for a two-hour checkout.

The Textbook Collection spans 530 linear feet across two main libraries and three branch libraries, makes up $80 \%$ of the entire Course Reserves collection, and includes the current semester's textbooks plus textbooks from the previous two semesters. When a textbook is not adopted by a course for three consecutive semesters, we relocate the material to the general collection. With an average of 47,000 circulations per year, the textbooks comprise a large portion of our overall print circulation. We recognized students' need to quickly identify assigned textbooks, so our Digital Library Initiatives department created the Textbook Lookup Tool (see Figure 1). This tool uses data from the Bookstores and ReservesDirect, our Course Reserves system, to expose all physical materials related to a specific course, acknowledging that the Textbook/Course Reserves distinction is not meaningful to our users. 
FIGURE 1: "TEXTBOOK LOOKUP TOOL”

\section{$\underline{\text { Alt-Textbook at NCSU }}$}

The NCSU Libraries' commitment to textbook affordability and equity of access extends beyond our textbook collection and reserves. In 2010, the Libraries collaborated with the Physics department to license a physics textbook used for introductory courses. The Libraries paid a one-time licensing fee to allow all NC State students to have free access to this textbook. The impact of this program on our students did not go unnoticed, and it became the first step for the Libraries in taking a leadership role to provide open and/or free learning materials to students.

In 2013, recognizing financial pressures facing our students and the opportunity to address them through collaboration with faculty to seed innovation, the NCSU Libraries began developing our AltTextbook project. This program was inspired by similar programs hosted in the Temple University Libraries and University of Massachusetts at Amherst Libraries. Like these programs, NCSU's AltTextbook project provides small grants of between $\$ 500$ and $\$ 2,000$ to individual instructors who are willing to replace an existing, commercial textbook with an open resource.

The Alt-Textbook project has successfully converted 20 courses to open or free educational resources, easing the financial burden of textbooks on our students by over $\$ 300,000$. This project has not only attracted faculty looking to reduce the cost of their learning materials, but also faculty who are eager to create or use innovative resources that do things a traditional textbook can't. These resources have included, among other media, student-made videos, 3D-scanned files and renderings, remixed popular articles, interactive tutorials, and iterative courses developed through versioning tools like GitHub. These textbooks are not only free to use, but they have added value that is not provided by a print resource. 
Our approach to textbook affordability is multi-pronged, including Alt-Textbook, Textbook Lending, and Course Reserves. This array of programs provides options for instructors to reduce costs for their students in multiple ways and also provides outlets for the Libraries to have an impact on affordability independently of course instructors. In 2016, we began to bridge these efforts by studying usage, course enrollment data, and cost to identify courses and instructors for targeted alternative textbook outreach.

This analysis relied on a foundation built by our Collections \& Research Strategy and Access Services departments to perform data-intensive collection management. Collections \& Research Strategy has direct access to interlibrary loan data through ILLiad, OCLC, and RapidILL and to circulation data through our integrated library system (ILS). Collections \& Research Strategy reviews the mostrequested books and journals via interlibrary loan and circulation holds, uses this data to inform purchasing decisions, and reports these decisions back to Access Services so that requests can be filled appropriately with accurate information provided to our patrons. Our study of the textbook lending program to inform OER outreach relied on circulation data from the ILS and cost and enrollment data from the NCSU Bookstores.

\section{Textbook Lending as Support for Alt-Textbook, Openness, and Advocacy}

Data was gathered from the Textbook Collection in the summer of 2016 in order to identify a "sweet spot" for engagement based on high-impact materials that were high cost, heavily used, and assigned to a large number of students. The data was drawn from two primary sources: internal circulation data from our ILS and data about materials shared with us by the Bookstores. From our ILS, we gathered data on textbook lending transactions from the fall and spring semesters from Fall 2014 to Spring 2016. Data from summer sessions was not included. From the Bookstores, we gathered a list of 
official textbooks, including the price of the materials and enrollment data for the courses where the materials were assigned.

We then linked the usage and semester data and crosswalked the qualities of the Bookstore data to the usage data in our collections. Over the four semesters examined, this data included 4,494 textbooks used across 2,158 courses, which included 13,163 individual sections. Because some courses required multiple textbooks, the number of assigned texts was significantly greater than the number of courses.

Table 1: “MATERIALS IN THE TEXTBOOK COLLECTION”

This data was analyzed by NCSU Libraries' Analytics Coordinator and Collections \& Research Librarian for Social Sciences John Vickery using SAS. Our goal was to identify materials that were in the top 25 percent of the collection across three areas: patron use of the materials, price of the materials, and enrollment in the course where the materials were assigned. Data analysis revealed several significant findings. First, as we had hoped, a clear set of low-hanging fruit emerged. Specific items and courses appeared consistently across semesters. The full list of materials is included in APPENDIX A. As described in Figure 2, materials in the top 25 percent saw a significant increase across all three areas, suggesting a somewhat heterogeneous collection with materials that stood out from the group.

FIGURE 2: "ITEMS IN THE TOPIC 25\%"

These materials varied widely across disciplines, but the data did indicate that a large number of the most expensive materials came from science, technology, engineering, and math (STEM) fields. This may reflect NC State's STEM focus as an institution, confirm the conventional wisdom that STEM 
materials are more expensive, or reflect other variables we have not considered. A much clearer finding was that introductory courses were disproportionately represented in our top 25 percent list. As with STEM materials, this matches the conventional wisdom in terms of cost, but also may confirm the assumption that introductory courses assign materials that some students would prefer not to purchase since they may not be in a student's area of focus and thus be reused to supplement upper- level courses or be valued as part of a personal or professional library. As discussed below, however, this is only conjecture and is an area that may merit further study.

Our study did not capture items that only ranked highly on two of the three identified categories such as an expensive textbook in a low-enrollment course. It also did not completely answer the seemingly simple question of how much money the Textbook Collection is actually saving students. As discussed below, the assumption that every transaction represents a student foregoing a textbook purchase is likely to be inaccurate, so the Libraries has done some preliminary estimations on costsavings, but further research is needed.

Using transactions in the ILS, James Cheng, a Fellow in the Libraries, was able to identify anonymized unique users. With 7,158 unique user circulations multiplied by the price variable per item, we could estimate a total savings of $\$ 764,561.96$. Recognizing that many students do not purchase every assigned textbook, however, we generated a more realistic estimate for a single semester's potential reduced financial burden on students by multiplying unique user circulations of each textbook by the textbook's cost, and then by 65\%, which the United States Public Interest Research Group (PIRG) estimates as the percentage of students who do not purchase textbooks (see Figure 3). This resulted in an estimated savings of $\$ 496,965.27$ for the spring 2016 semester.

FIGURE 3: "FORMULA FOR CALCULATING REDUCED FINANCIAL BURDEN" 


\section{Next Steps}

In addition to highlighting opportunities for further research, this data has given the Libraries an important tool for advocacy. Our findings represent a roadmap to inform future advocacy for our AltTextbook program, a mini-grant program that supports the adoption, remixing, or creation of open educational resources. Using the data, and leveraging our existing relationships, we are working to target courses that this data has identified as placing a significant financial burden on our students. Instead of cold-calling each faculty member who teaches a course on our list, we have been working with our subject-specialist librarians, who have close and meaningful relationships with faculty members, to identify any overlap between these relationships and high-impact courses. We have asked these subject specialists to reach out to amenable faculty -- especially those who may be considering a course redesign -- to start a dialogue about the cost of their textbooks, and to invite these faculty to any events or information sessions about open education. Additionally, we have engaged these librarians to help identify possible barriers to adoption of open textbooks that may be more difficult to address. For example, a handful of courses on the list use textbooks that were written by the faculty who use them, or a department head or other colleagues, which could reduce the incentive to make a change.

We have also used the data to understand and engage our student population. When speaking to students, we no longer need to rely on national averages to understand the financial burden that textbooks place on students; we now have an understanding of the specific reality of textbook costs at NC State. Armed with this data, we have reached out to students on campus to talk about open education: we have set up pop-ups in the main library's lobby, engaged with the Libraries' student advisory forum, and had one-on-one conversations with our student government representatives. In 2017, we addressed our Student Senate to begin developing joint efforts focused on textbook affordability. We have been able to connect with our students over their experience, and this understanding has helped us engage them in conversations that empower student advocacy for open 
educational resources. These conversations have also helped us to spread the word about the Libraries' commitment to textbook affordability, including our textbook lending program, engendering recognition and appreciation of the Libraries.

We have also split the focus of our Alt-Textbook grants in two, one which encourages the creation of new and innovative open course materials, and one which incentivizes the adoption of existing materials with an emphasis on significant student savings. In the past, faculty have been motivated to apply for Alt-Textbook grants by the opportunity to try new pedagogical techniques and technologies. These faculty instructors have created exceptional new course resources, funded by minigrants. However, for some faculty with major research grants and multiple competing priorities for their time, or who are content with their commercial textbooks, these mini-grants do not move the needle. Splitting the focus of our program allows us to continue to fund innovative courses, while finding new ways to encourage adoption to enable student savings.

For example, though we identified single-section courses in our data, many of the courses we identified had multiple sections. These courses are often managed at the departmental level. Our minigrants have been appealing to many individual faculty members, but these mini-grants are unlikely to persuade a department to change its assigned readings across multiple sections of a course. In order to engage these department-level courses, we are introducing larger, department-level grants for adoption, knowing that the return on investment will be much higher. By splitting the focus of our minigrant program, we are able to introduce new incentives such as these department-level grants.

In order to better contextualize the results of this study, further analysis is needed to understand how our students make use of our Textbook Collection. As previously mentioned, we cannot simply assume that each unique circulation of a textbook represents a student who did not purchase a book. The reality of our Textbook Collection is potentially much more complex. It is possible that our Textbook Collection could save more students from back pain than wallet pain. That is, our students 
could be using textbooks from the Libraries' collection that they already own simply because the book itself is too heavy to carry with them all day. Conversely, students could be checking out textbooks from our collection, scanning the book in part or in its entirety, and distributing the file to a group of their friends or classmates, so a single checkout may be benefitting many students. The reality is probably a mix of these and other behaviors. Further qualitative study, including student interviews and observation, could contextualize this data.

\section{Conclusion}

The cost of textbooks represents a major challenge for higher education. Students find themselves trapped in a broken textbook market where their purchasing decisions are made by faculty instructors but they are left to foot the bill. In response, students engage in what we call "student survivalism:" opting out of some classes and majors and often delaying or declining to purchase assigned readings, setting them back by weeks of study or simply leaving them hopelessly behind their wealthier peers. These students -- who are disproportionately first generation and from underrepresented populations -- need help navigating this space. Libraries can offer this help, which supports student success but also demonstrates library values of access and strategic collection of resources. Libraries can also help an institution meet its mission by reducing textbook costs that drive retention and keeping the doors open to "expensive" majors like STEM and business.

In order to offer this support, libraries need information about the use of textbooks on their campus and a strategy for engaging with campus stakeholders. They also need evidence that provides the institutional will to dedicate staff time and budget resources to these programs. This study offers a window into this data that can guide action. By analyzing collection and circulation data, we have begun to map our campus' textbook environment, marking trouble spots and charting paths forward. It confirmed some of our conventional wisdom, corrected some misunderstandings, and illuminated new 
areas for future investigation. Whether nurturing a nascent open education program, building on success, or pivoting in a new direction, this type of analysis can help any library to better understand the needs of its community. Whether saving students money or backaches, library-led textbook initiatives demonstrate the library's value to the institution as a partner that understands and is working to address student academic needs and concerns. 


\section{Figures and Tables}

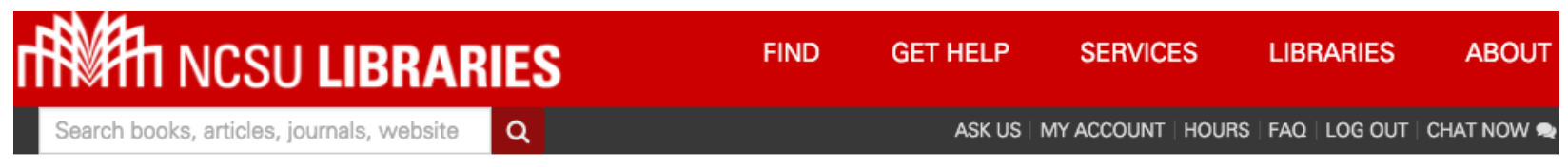

Each fall and spring semester, the Libraries works with the NC State Bookstores to purchase at least one copy of every required textbook and make them available on Reserve.

Search by course

Curriculum code

Course number

Search by course titles, instructor last name, curriculum, or course number

Course information

Please note: this is only a partial list of the most relevant results.

Please use the curriculum code search tool to view all courses

within a curriculum.

Figure 1. NCSU Libraries Textbook Lookup Tool

\begin{tabular}{|r|r|r|r|}
\hline \multicolumn{4}{|c|}{ By Semester } \\
\hline Semester & Textbooks & Courses & Sections \\
\hline Fall 2014 & 2,039 & 1,250 & 3,767 \\
\hline
\end{tabular}




\begin{tabular}{|l|r|r|r|} 
Spring 2015 & 1,735 & 1,083 & 3,085 \\
\hline Fall 2015 & 1,894 & 1,121 & 3,355 \\
\hline Spring 2016 & 1,764 & 1,069 & 2,956 \\
\hline
\end{tabular}

Table 1: "Materials in the Textbook Collection"

\section{Enrollment}

Overall average $=64$

Average of the top 25\% list $=230$

\section{Bookstore price}

Overall average $=\$ 64$

Average of the top 25\% list $=\$ 163$

\section{Usage}

Overall average $=16$

Average of the top 25\% list $=74$

Figure 2: Items in the Top 25\%

$$
\begin{gathered}
(\# \text { unique user circulations } \times \text { price }) \times \% \text { of students not purchasing textbooks } \\
=\text { potential reduced financial burden }
\end{gathered}
$$

Figure 3: "Formula for calculating reduced financial burden." 